\title{
Research on the Construction of Cross-border E-commerce Ecological Circle in Shaanxi from the Perspective of Value Net Theory
}

\author{
Jiang Yu \\ Xi'an International University, Xi'an, Shaanxi, 7100771, China
}

Keywords: Cross-border E-commerce Ecological Circle, Value Net Theory, Construction Method

\begin{abstract}
The application of the Internet has brought about major changes in the world economic structure. The construction of a cross-border e-commerce ecosystem has become an important support for the development of SMEs. Through the construction of a cross-border e-commerce ecosystem, the world economy has been integrated into a new development. Judging from the current situation, there are still some problems in the construction of cross-border e-commerce ecosystem under the support of the Internet. It is very important to study it and explore the corresponding development path.
\end{abstract}

\section{Introduction}

Computer technology and communication technology continue to innovate and advance, making enterprises use Internet technology for business activities, and they are rapidly developing and creating tremendous influence. Network information is a 24-hour library that uses the Internet to gain a knowledge base of global information. Intel President Grove has said that the future business will be electronic, and in the future, all companies will become network companies. E-commerce is considered to be a business model with competitive advantages in the era of digital new economy. The construction and innovation of the e-commerce business model is not only a method of constructing and innovating the components of the business model, but also the value chain construction is a common business model construction analysis method. The value chain's approach to building a business model emphasizes that the new business model is a variable that hides the general value chain under all business activities. The value chain consists of two parts: one part includes all production-related activities, such as designing, purchasing raw materials, and manufacturing; the other part includes all sales-related activities, such as finding and contacting customers, transactions, distribution channels, and after-sales services. Link. A new business model can be the adjustment and innovation of one or more parts of the value chain.

\section{Development of e-commerce business model based on value network theory}

Although the development of e-commerce has been devastated by the dot-com bubble economy, many research results show that the current e-commerce of enterprises is undergoing sound development, and the long-term development of the industry is more beneficial than disadvantages. The problem faced by many e-commerce websites is that virtual space trading websites have not found a way to operate physical stores, and physical stores have not developed a business model suitable for virtual space. The interactive behavior and transaction content of the physical store gradually turned to the virtual space trading method. Virtual space basically plays the role of providing three values: (1) creating new value (2) increasing added value (3) extending the existing value, and not causing the myth of value, leading to a serious bubble in the network. Creating new value means showing information that the entity can't or can't easily convey, such as virtual reality simulation and creating the realm of human conception. Through the application of information, it can be tailored to customers. Enhancing added value means promoting the original The value of physical goods and services, such as the transmission of marketing and service customers' information through the network, increasing the sales and utilization of goods; extending the existing value refers to the large amount of data stored and processed by the information tools. In a 
digital trading environment.

\section{Main issues of the components of the cross-border e-commerce ecosystem}

At present, there are still many problems in the constituent elements of China's cross-border e-commerce ecosystem. Firstly, the integration of cross-border logistics systems and cross-border e-commerce ecosystems is obviously insufficient. In order to ensure the continuous and effective operation of the cross-border logistics system, it is necessary to ensure that there is sufficient logistics infrastructure, and the dynamics of the cross-border logistics transportation system also needs to be supported by a solid and reliable cross-border logistics infrastructure. Therefore, the current cross-border electricity The problem facing the composition of the business ecosystem is how to improve and improve the infrastructure construction of the cross-border logistics system. In the process of cross-border e-commerce business development, transportation methods such as maritime transport, air transport and land transport are indispensable to realize the handover process of the business. The consequence of the lack of transport business in China is to bring unnecessary problems to the cross-border logistics system. Trouble, and increase the cost of transportation, is not conducive to the operation of the entire cross-border e-commerce ecosystem. On the other hand, modern transportation infrastructure lacks the ecological integration of cross-border e-commerce. The operation of cross-border e-commerce is mainly based on the logistics system. Therefore, the construction of the logistics system is the core content to ensure the good operation of cross-border e-commerce. Only the good transportation mode and the logistics infrastructure such as the logistics center can be compared. It is necessary to realize the smooth development of cross-border e-commerce business and promote the construction of a cross-border e-commerce ecosystem under the Internet vision.

The shortcomings of the cross-border e-commerce ecosystem are also reflected in the lower customs clearance process and its ecosystem. The first thing that comes out is that the customs import and export cargo supervision business has a low degree of fit with cross-border e-commerce. The main function of the customs system is to regulate the customs clearance of import and export goods. It mainly involves many processes and departmental functions such as customs, banking, industry and commerce, taxation, commodity inspection, etc. Only the customs clearance and coordination of customs can be effective. Improve the fit between the remaining cross-border e-commerce ecosystems, thereby promoting the formation of a cross-border e-commerce ecosystem. At present, there is a common gap between the various departments of customs in China, and there are vacant areas in the division of functions. It is unable to meet the comprehensive supervision effect on the customs operation process, which leads to the unreasonable resources and resources of the customs for the cross-border e-commerce business. The waste phenomenon has raised the customs clearance costs of cross-border e-commerce. In addition, there is a clear gap between the existing customs clearance model of the customs system and the cross-border e-commerce system. The main purpose of the development business of cross-border e-commerce is to meet the demand of foreign customer groups for commodities. The current uncertainty of cross-border e-commerce to foreign target customers has caused great obstacles to business operations in domestic industries. E-commerce companies cannot accurately predict the status of foreign markets and formulate effective commodity transportation plans in a timely manner. This leads to the full consideration of the commodity market conditions in the process of shipping e-commerce products in China, which not only increases the difficulty of sales of goods, but also invisibly Increased cost of goods sold and reduced economic returns.

The imbalance between the domestic cross-border e-commerce market operation and the cross-border e-commerce ecosystem is not conducive to the stable and sustainable development of the industry. The cross-border e-commerce industry should pay attention to the cultivation of talents who are sufficiently proficient in cross-border market operations. Recruiting, as a comprehensive engineering cross-border e-commerce operation model, only relying on the management process of comprehensive talent efforts can achieve the control and opening up of cross-border e-commerce business between the two markets. This is inseparable from the management of business talents 
who are proficient in cross-border market operations. Therefore, attaching importance to professional operations management talents and strengthening the professionalism of cross-border e-commerce market management is the main way of cross-border e-commerce operations. And as an emerging industry, cross-border e-commerce still lacks sufficient experience and understanding of the consumer attitudes of foreign customers. Different countries have different cultures and habits of thinking, which inevitably lead to different consumption concepts. This makes the development of cross-border e-commerce business not blindly interpret with a simple price quantity model. It only combines local cultural characteristics and consumer interests. Achieving targeted guidance on the actual operating model can correctly promote the maximum recognition of product quality and service by foreign target groups.

\section{Cross-border e-commerce ecosystem construction strategy}

In order to build a cross-border e-commerce ecosystem under the "Internet +" horizon, optimizing the organizational structure of the cross-border e-commerce ecosystem is currently the most reasonable and effective way. First of all, cross-border e-commerce should clearly follow the core peripheral principles to build an ecosystem system that adapts to the "Internet + " environment, emphasizing the construction of individualized features in the cross-border e-commerce ecosystem, thereby ensuring the industrial clusters in the process of building the ecosystem. Spatial concentration. By striving to stabilize and rationalize the organizational structure of the cross-border e-commerce ecosystem around the e-commerce operation platform, it is possible to effectively aggregate the operational benefits related to cross-border e-commerce business and promote the maximum resources among various stakeholders. Utilize to create a cross-border e-commerce platform with a certain level of cyberspace radiation capability in the world. In order to effectively realize the process of optimizing the organizational structure of the cross-border e-commerce ecosystem system, the core business cluster should be built around the superior resources of cross-border e-commerce, and the main development direction of the core business should be realized with the main advantages of the business content. The network-based cross-border e-commerce business cluster, which is mainly supported by related industries, further promotes the construction of a cross-border e-commerce ecosystem under the "Internet +" horizon.

Improve the cross-border logistics support for cross-border e-commerce through the business and logistics integration development model, thereby improving the cross-border logistics operation level of cross-border e-commerce, and relying on the model of the interconnection platform to realize the business flow of international trade business. Activities, combined with cross-border logistics goods cross-border business cooperation, to promote the effective implementation of international trade operations. Compared with cross-border e-commerce, cross-border logistics business has more complex business levels and higher risk of goods circulation characteristics, which determines the cross-border logistics to cross-border e-commerce business development of the mutual constraints. At the same time, by optimizing the cross-border logistics business process, the degree of integration between cross-border logistics and cross-border e-commerce can be effectively improved. Taking into account the high risks and uncertainties inherent in the cross-border logistics business, combined with the high cost of cross-border logistics, it should reasonably strengthen the capital investment in overseas warehousing, multimodal transport and fast customs clearance, thus creating An operating system that is more efficient and effectively controls logistics costs.

In order to strengthen the construction of the cross-border e-commerce ecosystem under the "Internet +" perspective, attention should be paid to improving the customs clearance procedures for cross-border e-commerce. Only the coordination and communication between the customs regulatory agencies and the export business departments can play a positive role in promoting cross-border e-commerce business, so as to better realize the convenience of cross-border e-commerce business. At present, there is still a big contradiction between the international customs and the products and services provided by cross-border e-commerce. Only strengthening the construction of the customs system can ensure that the customs' supervision of commodities is not 
reduced. Improve the effectiveness and effectiveness of customs supervision work. Improve customs clearance procedures for cross-border e-commerce, including improving the customs clearance port of the customs system, ensuring that cross-border e-commerce can easily use the electronic port to report relevant customs declaration materials to the customs supervision department at one time; the customs supervision department can The cross-border e-commerce customs clearance materials were reviewed online and received timely feedback.

\section{Conclusion}

The construction of cross-border e-commerce is an important support and path for the development of SMEs. Especially in the current Internet environment, it is even more important to research and develop it. Relevant personnel need to explore and practice under the existing conditions, rely on the Internet to develop a new business model and logistics model for cross-border e-commerce, and improve and enhance the construction process of Chinese enterprises in the Internet cross-border e-commerce ecosystem. Get better development and make it an important driving force for China's economic development.

\section{Acknowledgements}

Fund Project: 2017 Shaanxi Provincial Department of Education Scientific Research Project: Research on the Construction of Cross-border E-commerce Ecological Circle in Shaanxi from the Perspective of Value Network Theory, No.: 17JK1086

\section{References}

[1] Wu Min ". Internet +" perspective of cross-border e-commerce ecosystem construction path analysis [J]. Business Economics Research, 2015, (34): 75-76.

[2] Li Xianxiong. Exploring the Teaching of Cross-border E-commerce Curriculum Module for Internet+ [J]. Journal of Guangdong Teachers University of Technology, 2016, (6): 133-140.

[3] Zhang, Xu Xiangyang. Creating the best cross-border e-commerce ecosystem to achieve the "only" to "first" transformation [J]. Hangzhou (Weekly), 2016, (12): 44-45.

[4] Zhang Wei. China's cross-border e-commerce ecosystem layout planning from the perspective of platform strategy [J]. Journal of Business Economics, 2016, (18): 87-88.

[5] Li Wei. The change and development of cross-border e-commerce in the era of Internet $+[\mathrm{J}]$. Shopping mall modernization, 20 